\title{
GENE POOL OF SCOTS PINE (PINUS SYLVESTRIS L.) UNDER REFORESTATION IN EXTREME ENVIRONMENT
}

\author{
Yulai Yanbaev, Rida Sultanova, Liubov Blonskaya \\ Svetlana Bakhtina \\ Bashirir State Agrarian University \\ Russia \\ Albina Tagirova, Vadim Tagirov \\ Bashikir State University \\ Russia \\ Aleksey Kulagin \\ Ufa Institute of Biology of Ufa Research Center of Russian Academy of Sciences \\ Russia
}

(Received August 2019)

\begin{abstract}
The article is devoted to the study of the gene pool formation mechanisms of arboreal plant populations at the sites of mining and processing of mineral resources and may be useful in managing the processes of natural forest remediation of disturbed lands. The aim of the research is to study the genetic diversity and spatial differentiation of the Scots pine (Pinus sylvestris L.) undergrowth thriving on the industrial waste discharge of the Uchaly Mining and Processing Plant (the Southern Urals).

Isoenzymes of 7 enzymes were used as markers (encoded by 10 polymorphic loci Aat- 1 , Aat-2 and Aat-3, Gdh-1, Fdh-1, Lap-1, Lap-1, Skdh-1, 6-Pgdh-1 and Dia-1), separated by polyacrylamide disc electrophoresis. Genetic variability of the undergrowth under the forest canopy ( 7 samples, average number of avenues per locus $\mathrm{A}=2.3-2.8$, the observed heterozygosity was $\mathrm{H}_{\mathrm{O}}=0.207-0.260$, the expected heterozygosity $\left.\mathrm{H}_{\mathrm{E}}=0.201-0.273\right)$ and in industrial waste discharges (4 samples, $\mathrm{A}=1.9-3.1, \mathrm{H}_{\mathrm{O}}=0.225-0.277 ; \mathrm{H}_{\mathrm{E}}=0.240-0.298$ ) varies over a wide range. In the parent stand, the observed heterozygosity $\left(\mathrm{H}_{\mathrm{O}}=0.203\right)$ was lower than in any of the undergrowth samples. A comparatively high genetic differentiation of the undergrowth was found (the between-sample subdivision $\mathrm{F}_{\mathrm{ST}}$ index was 3.8\%, the average Nei genetic distance $\mathrm{D}_{\mathrm{Nei}}=0.015$ with changes in individual pairs from 0.003 to 0.032 ), comparable with genetic differences in geographically separated populations.
\end{abstract}

KEYWORDS: Gene pool, Pinus sylvestris, undergrowth, enzymes, markers, heterozygosity. 


\section{INTRODUCTION}

Industrial pollution of environment today has reached menacing proportions. Particularly serious are the consequences of the activities of mining and processing enterprises in mineral production region. According to official data State report on natural resources condition and the environment of the Republic of Bashkortostan. Ministry of Environment and Ecology of the Republic of Bashkortostan (2017), in the Republic of Bashkortostan (Russia) about 3,000 deposits and manifestations of 60 types of mineral raw materials are discovered. The reserves of the main metal minerals are: copper $-4,686.3$ thousand tons, zinc -5005.5 thousand tons. Here, from the middle of the last century, the Uchalinsky Mining and Processing Plant, its branch in Sibay, the Bashkir Copper-Sulfur Plant, the Buribaevsky Mining and Processing Plant, the 'Bashkir Med' Ltd Enterprise and other mine 10-12\% of copper and about $50 \%$ of zinc of all the mineral production in Russia. The large scale and duration of the mining and processing of ore, the open method of mining (Fig. 1) led to significant environmental pollution by such highly toxic components of ores (Chudzińska et al. 2014) as copper, zinc, iron, cadmium, lead, bismuth, cobalt, selenium, tellurium, sulfur, antimony, fluorine, etc. for example, compared to background values, wastewater in the area of industrial waste discharges of zinc and copper are 31-102 times and 374-6074 times more, respectively (Belan 2005). In soils bulk compounds of zinc are 5-50 times more than background indicators, copper are more than up to 10 times. The concentration of active forms of $\mathrm{Cu}$ in the soil reaches 12 and $\mathrm{Zn}-3.3$ admissible concentration limit. Heavy metals, migrating through the food chain, pose a threat to plants and animals and human health. For this reason, the work on the remediation of such man-made territories is extremely important (Mahar et al. 2016).

Taking into consideration the high cost of such works, in the conditions of Russia in the forest zone, the use of natural overgrowing of man-made territories by trees and shrubs is promising. Such a pioneer species as Scots pine (Pinus sylvestris L.), which is one of the main forest formers of Eurasia, has a particularly high potential (Gabdrakhimov et al. 2018, Sultanova et al. 2018). For this reason, studies of plant adaptation mechanisms to extreme environmental conditions in man-made areas are relevant (Kulagin and Tagirova 2015). The effect of industrial pollution on genetic variability, intra- and inter-population differentiation in scots pine stands has been studied in sufficient detail (Yanbaev 2002, Chudzińska et al. 2014, Prus-Głowacki and Nowak-Bzowy 1992, Sherameti and Varma 2015). We studied the subpopulations of the same stand, damaged by industrial pollutants in varying degrees (groups of "resistant" and "sensitive" trees). The indicators of genetic polymorphism of different generations of populations were also compared. But the reproduction peculiarities of the population's gene resources in young stand with the overgrowing of man-made territories by this species have little if any been studied. In Poland, comparative studies of polymorphism of 10 isoenzyme loci of 10-15 years old young stand growth that thrive under zinc contamination conditions and 9 natural crops outside the territory of technogenic pollution have been carried out (Prus-Głowacki and Nowak-Bzowy 1992). The revealed significant differences in the genotypic composition of these age groups indicate the prospects of such research for studying the adaptive strategy of a species under the conditions of technogenesis. Knowledge of the genetic structure formation mechanisms of the new generation of pine forests in the man-made areas can be useful not only for science, but also for managing the necessary processes of natural forest remediation of disturbed lands. The purpose of this research is to study the genetic diversity and differentiation of the common pine undergrowth, which grows under the conditions of heavy metals contamination. 


\section{MATERIALS AND METHODS}

On the territory of the Uchaly Mining and Processing Plant (hereinafter UMPP, geographic coordinates of its center: $\mathrm{N} 54^{\circ} 18^{\prime} 33^{\prime \prime}$ and E $59^{\circ} 25^{\prime} 22^{\prime}$ ), natural pine and birch forests (Fig. 1) come from the northern and eastern sides of the quarry, which are the source of seed supply and reforestation of industrial waste discharge. Basically, undergrowth of Scots pine of different thickness and age is available at the foot and slopes of industrial waste discharge.

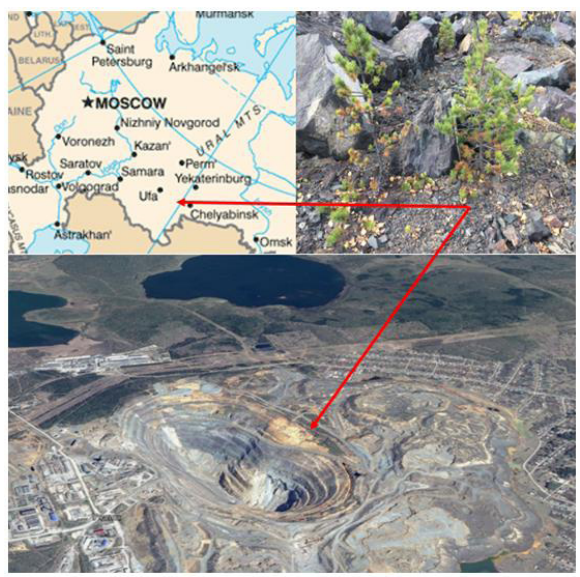

Fig. 1: Territory of the Uchaly mining and processing plant. Red arrow - the location of collected samples.

In this part of their perimeter in 7 clumps of trees (trial plots are designated as SDU1, SDU2, SDU3, SDU4, SDU5, SDU6 and SDU7), 32 samples of undergrowth were selected from which winter buds were collected for laboratory analysis. The samples were also collected from 32 trees of a nearby pine stand (TSU), located northeast at a distance of about $300 \mathrm{~m}$ from the waste discharges. 32 samples of buds were divided into 4 groups of undergrowth (SSU1, SSU2, SSU3, SSU4) growing under the canopy of this plantation, which stretches for $5 \mathrm{~km}$ along the eastern side of the waste discharges. One more sample (SDS) of the same size is the undergrowth of industrial waste discharge of another enterprise located about $200 \mathrm{~km}$ to the south of the Bashkir Copper-Sulfur Plant. The age of the undergrowth in all cases was up to 20 years.

Molecular and genetic DNA markers are increasingly being used for population genetic studies of arboreal plants (Forrest et al. 2000), including the use of highly efficient methods of new generations (Blanc-Jolivet et al. 2018). However, in this research, we used enzyme electrophoresis and isoenzyme markers. This allowed us to compare the data obtained with the previously obtained extensive results of studying the genetic structure of natural populations of Scots pine in the Southern Urals (Yanbaev 2002), as well as from scientific literature (Chudzińska et al. 2014, Forrest et al. 2000, Goncharenko et al. 1993, Larionova and Ekart 2011, PrusGłowacki and Nowak-Bzowy 1992, Savolainen and Hedrick 1995, Sherameti and Varma 2015, Wójkiewicz et al. 2016). The enzymes were extracted using $0.1 \mathrm{M}$ Tris- $\mathrm{HCl}$ ( $\mathrm{pH}$ 8.0) buffer containing $17 \%$ of sucrose, $0.1 \% 2$-mercaptoethanol and $0.05 \%$ of sodium diethyldithiocarbomate. A portion of $200 \mathrm{mg}$ hybernaculum pieces was ground in a porcelain mortar with the addition of $1 \mathrm{ml}$ of chilled extraction buffer. To bind polyphenols, about $200 \mathrm{mg}$ of insoluble Polyclar AT polyvinylpyrrolidone was added before. The homogenate was centrifuged for 20 minutes at 15-17 thousand rpm in the refrigerator. The separation of isoenzymes was carried out by 
the method of disk electrophoresis in vertical plates of $7.5 \%$ polyacrylamide gel with a $\mathrm{pH}$ of separating gel of 8.9 (Davis 1964, Ornstein 1964) using a tris-glycine electrode buffer with a $\mathrm{pH}$ of 8.3. Histochemical detection of enzyme activity zones in gels was carried out according to standard methods (Larionova and Ekart 2011) with minor modifications. We studied the variability of aspartate aminotransferase (AAT, E.C. 2.6.1.1), glutamate dehydrogenase (GDH, 1.4.1.2), formate dehydrogenase (FDH, E.C. 1.2.1.2.), Leucine aminopeptidase (LAP, 3.4.11.1), shikimate dehydrogenase (SKDH, 1.1.1.25.), 6-phosphogluconate dehydrogenase (6-PGD, 1.1.1.44) and diaphorase (DIA, 1.6.4.3).

To characterize the variability and the level of division of populations, 10 polymorphic loci were used: Aat-1, Aat-2 and Aat-3, Gdh-1, Fdh-1, Lap-1, Lap-1, Skdh-1, 6-Pgdh-1 and Dia-1 (Yanbaev 2002). To analyze the level of genetic variability and differentiation of samples, the indicators determined by the BIOSYS-1 program (Swofford and Selander 1981) are used - the frequency of alleles, their number per locus (including using the $5 \%$ criterion), the observed and expected heterozygosis, the level indicator of the inter-election subdivision of $\mathrm{F}_{\mathrm{ST}}$ of Wright's F statistics, M. Nei's genetic distance D (Nei 1972). The differences in the observed distributions of genotypes and their expected frequencies at the Hardy-Weinberg equilibrium were determined using the standard - criterion. In addition, for this purpose, a test was also used with a combination of genotypes into three classes: 1) a homozygous for the main allele, 2) a heterozygote for the main allele, 3) all other genotypes. These calculations were performed using the GSED program (Genetic Structures from Electrophoresis Data (GSED) (Elizabeth M. Gillet).

\section{RESULTS}

In the studied samples, only two loci were diallel - Aat- 1 and Dia- -1 . The remaining loci had three alleles (3 loci), four alleles (3 loci), and five alleles (3 loci). The maximum number of alleles, six, was detected at 1 locus (Tab. 1). In the remaining three loci with 4 alleles, not only rare allozymes were revealed - polymorphism was also found for more frequent alleles. In the reforestation of anthropogenic land of UMPP involved not only the nearby stand, but also other, more distant, pine stand. This is proved by the fact that almost half of the identified alleles of young undergrowths (18 out of 39 or $46.2 \%$ ) are not found in the trees of the nearby stand. As a pioneer species, scotch pine is capable of efficiently spreading seeds over relatively long distances, which should lead to the formation of a genetically homogeneous seed pool. However, a particularly high concentration of certain alleles in individual habitats was noted.

Tab. 1: The number of alleles at the given Loci.

\begin{tabular}{|l|c|}
\hline Locus & No. of Alleles \\
\hline Aat-1 & 2 \\
\hline Dia-1 & 2 \\
\hline GDH & 3 \\
\hline Lap-1 & 4 \\
\hline Lap-2 & 4 \\
\hline Skdh-1 & 4 \\
\hline Aat-2 & 5 \\
\hline Aat-3 & 5 \\
\hline Fdh-1 & 5 \\
\hline 6Pgdh-1 & 6 \\
\hline
\end{tabular}


For example, the 6-Gdh- $1^{3}$ allele was not found in 8 undergrowth samples, in 2 of them, two plants are carriers of the allele with a frequency of 0.016 . But in one sample it is found with a frequency of 0.125 . In loci that showed a particularly high inter-sampling subdivision, deviations of the observed distributions of genotypes from theoretically expected frequencies were revealed (Tab. 2).

Tab. 2. Loci with deviations of genotype distribution.

\begin{tabular}{|c|c|c|}
\hline \multirow{2}{*}{ Sample } & Locus & $\begin{array}{c}\text { Deviation from expected genotype distribution, } \\
\text { significance level }\end{array}$ \\
\hline SDU3 & 6-Pgdh-1 & $\mathrm{p}<0.01$ \\
\hline \multirow{2}{*}{ SSU3 } & Lap-2 & $\mathrm{p}<0.01$ \\
\cline { 2 - 3 } & Skdh-1 & $\mathrm{p}<0.01$ \\
\hline \multirow{2}{*}{ SSU4 } & Lap-2 & $\mathrm{p}<0.05$ \\
\cline { 2 - 3 } & 6-Pgdh-1 & $\mathrm{p}<0.01$ \\
\hline SDU1 & 6-Pgdh-1 & $\mathrm{p}<0.05$ \\
\hline
\end{tabular}

In our opinion, this phenomenon is associated with a relatively large contribution of individual mother trees to the formation of undergrowth in one or another part of industrial waste discharges. The parent stand adjacent to the waste discharges is pine-birch, in which the proportion of Scots pine varies greatly. In some places, the 'wall' of the stand is very dense due to thick birch and young pine forest. Fruit-bearing Scots pine trees of the reproductive age are sometimes rarely represented along the planting boundary. Under these conditions, a local concentration of certain parent alleles, less frequent in the entire population, or a decrease in their frequencies can be observed.

The average sample of undergrowth in the area of UMPP reveals a relatively high allelic diversity compared with the parent stand. This superiority is due to rare alleles. With the introduction of a $5 \%$ polymorphism criterion, the indicator $(\mathrm{A}=1.7 \pm 0.1)$ decreases even to a lower level compared to a sample of trees. The expected heterozygosity of the undergrowth on the man-made lands of UMPP $\left(\mathrm{H}_{\mathrm{E}}=0.264 \pm 0.007\right)$ and the trees in the parent stands are almost the same. But in the parent stands, the observed heterozygosity $\left(\mathrm{H}_{\mathrm{O}}=0.203\right)$ was lower than in any of the undergrowth samples. This phenomenon may be the result of a relatively high proportion of rare alleles in the reforestation of industrial waste discharges and adjacent manmade lands (for statistical reasons, the probability of their meeting in a homozygous state is less).

Genetic variability in groups of undergrowth samples under the forest canopy ( $\mathrm{A}=2.5 \pm 0.1$, changes from 2.3 to $2.8 ; \mathrm{H}_{\mathrm{O}}=0.234 \pm 0.011,0.2007-0.260 ; \mathrm{H}_{\mathrm{E}}=0.247 \pm 0.016,0.0101 .2 .273$ ) and on industrial waste discharges $\left(\mathrm{A}=2.4 \pm 0.21 .9-3.1 ; \mathrm{H}_{\mathrm{O}}=0.244 \pm 0.007,0.225-0.277\right.$; $\left.\mathrm{H}_{\mathrm{E}}=0.262 \pm 0.007,0.240-0.298\right)$ varies over a wide range. 
Tab. 3: Frequencies and proportion of genetic variation in Loci.

\begin{tabular}{|l|c|c|}
\hline \multicolumn{1}{|c|}{ Locus } & Frequency of change in genetic composition & Proportion of genetic variation, $\mathbf{F}_{\mathbf{S T}}(\mathbf{\%})$ \\
\hline Skdh-1 & $0.844-0.969$ & 1.9 \\
\hline Aat-2 & $0.625-0.766$ & 2.4 \\
\hline Fdh-1 & $0.828-0.969$ & 2.0 \\
\hline Lap-2 & $0.844-1.000$ & 6.5 \\
\hline Aat-3 & $0.604-0.800$ & 1.2 \\
\hline Dia-1 & $0.625-0.875$ & 3.6 \\
\hline Gdh-1 & $0.594-0.908$ & 6.1 \\
\hline 6Pgdh-1 & $0.438-0.906$ & 6.9 \\
\hline
\end{tabular}

The studied samples of common pine undergrowth are located at a short distance from each other - on a plot of about twelve square kilometres. However, the allele frequencies revealed a relatively high level of differences in the undergrowth samples. Only at the Aat- 1 and Lap-1 locus practically invariant alleles were found (Tab. 3). Some alleles show a particularly large genetic subdivision of the undergrowth samples of the man-made area of UMPP zone (Fig. 2).

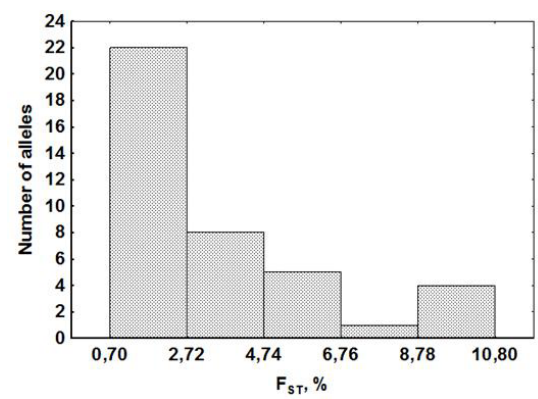

Fig. 2: Distribution of alleles by intersectional division.

For example, $\mathrm{F}_{\mathrm{ST}}$ values were 0.070 (6-Pgdh-12 allele), 0.089 (6-Pgdh-16), 0.100 (6-Pgdh-11), 0.092 (Gdh-13), 0.108 (Lap-22). The relatively large heterogeneity of the studied samples according to the number and frequency of alleles is not a consequence of the inclusion the stand (TSU sample) and undergrowth from industrial waste discharges of another mining enterprise (SDS) into the analysis. Confirmation of this was obtained when calculating not only the indicator of inter-sampling subdivision of $\mathrm{F}_{\mathrm{ST}}$ (on average, per one locus 3.8\%), but also genetic distances between samples. On average, a value of $\mathrm{D}=0.015$ is obtained with changes in individual pairs from 0.003 to 0.032 .

Tab. 4: The number of pairwise genetic distances between samples.

\begin{tabular}{|c|c|}
\hline Pairwise genetic distance between samples, $\mathbf{D}$ & No of cases \\
\hline $0.001-0.006$ & 15 \\
\hline $0.006-0.013$ & 29 \\
\hline $0.013-0.019$ & 26 \\
\hline $0.019-0.026$ & 13 \\
\hline $0.026-0.032$ & 5 \\
\hline
\end{tabular}


With the exclusion from the analysis of the parent stand and the selection of undergrowth from the Bashkir copper-sulfur plant waste discharges, this value decreases insignificantly to $\mathrm{D}=0.012$ (0.003-0.028). The pairwise genetic distances between the samples varied significantly (Tab. 4).

\section{DISCUSSION}

Scotch pine (Pinus sylvestris L.) is a well studied species from the population-genetic point of view (Prus-Głowacki et al., 2006, Savolainen et al. 2011, Kujala et al. 2017, Wachowiak et al. 2011, Wójkiewicz et al. 2016). Comparison with the literature data allowed us to conclude that the level of inter-sampling differentiation of undergrowth identified by us on the man-made lands of the Uchaly Mining and Processing Plant was typical for differences in geographically separated populations: South Urals, North-West Russia (Yanbaev 2002), Eastern Europe and Siberia (Goncharenko et al. 1993), Krasnoyarsk Territory, Khakassia, Tuva and Altai Mountains (Larionova and Ekart 2011). The main cause of this phenomenon may be a large variability of sites in man-made polluted lands and industrial waste discharges.

Technogenic ecotopes here are highly differentiated topographically, according to the degree of phytotoxicity of soils, and also differ in the physical, chemical, mechanical, fractional and particle-size properties of rock formations, in the rates of primary soil formation (in many reforestation areas, there is physical weathering and accumulation of organic matter). Undoubtedly, such differences in environmental conditions should have a strong influence on the survival rate and growth course of the undergrowth. To demonstrate this phenomenon, we measured the value of the annual increase in height for the undergrowth of four samples located on the surface of the waste discharges (SDU1, SDU2 and SDU3) at their foot at the edge of the stand (SSU4). The obtained data were compared with a one-year increase in the height of the undergrowth groups growing also in well-lit conditions, but outside the direct impact of industrial pollution of the UMPP at a distance of about $20 \mathrm{~km}$ from the enterprise. On average, annual growth in technogenic conditions ranged from $9.5 \pm 1.5 \mathrm{~cm}$ (differences between plants within $4.1-20.2 \mathrm{~cm}$, coefficient of variation is $50.6 \%)$ to $56.7 \pm 1.6 \mathrm{~cm}(50.2-63.5 \mathrm{~cm}, 8.8 \%)$. In the control outside the industrial pollution zone, the following results were obtained: $57.2 \pm 3.2 \mathrm{~cm}, 39.2-72.4 \mathrm{~cm}$ and $17.5 \%$, respectively. Under natural conditions, as shown by a study, the annual growth of 28 undergrowth samples on abandoned agricultural lands (Tagirov et al. 2015) outside the direct impact of UMPP variability is much lower. Therefore, it is the contrast of the environmental conditions of the man-made lands of the enterprise that could cause such large differences in the growth of the young trees from different habitats of the man-made lands. Accordingly, plants from such different ecotopes should be subjected to different pressures of natural selection, which may lead (Prus-Głowacki and Nowak-Bzowy 1992) to a more pronounced differentiation in terms of genotypic composition. In this case there is a definite parallel with the effect of increasing the level of genetic differences in populations located in natural conditions in ecologically contrasting habitats. For example, 8 stands in the Tomsk region (the distance between 7 of them did not exceed $16 \mathrm{~km}$, and one is located $130 \mathrm{~km}$ from them) differed in the frequencies of alleles of isozyme loci even more than the populations of different regions - Krasnoyarsk Territory, Khakassia, Tuva and Altai Mountains (Larionova and Ekart 2011). However, in these researches, inter-sampling differences were determined at the population level.

Reproduction issues of the natural populations' gene pool of forest trees in technogenic conditions have attracted the researchers' attention all the time. A review of the results in this field obtained in 1991-2013 is given in the publication (Sherameti and Varma 2015). It has been 
shown that acute technogenic pollution leads to an increase in the heterozygosity of populations, partly owing to the peculiarities of the Scots pine breeding system. The species is characterized by inbreeding, the level of which depends on many environmental conditions (density of stands, climatic and weather conditions, flowering intensity, etc.) (Forrest et al. 2000). Young inbreeding individuals having a reduced viability and weaker growth due to inbreeding depression. In relatively favorable environmental conditions they are able to survive the early stages of ontogenesis (embryos, seedlings, undergrowth). But under extreme environmental conditions for Scots pine, the process can be eliminated more quickly, which leads to a greater increase in the observed heterozygosity of the surviving individuals. Perhaps this mechanism partially explains the greater heterozygosity of the undergrowth of industrial landfills compared with the maternal population, which arose more than 50 years ago till the creation of UMPP before the increase in pressure of natural selection due to its action. This process can be the cause of the revealed increase in allelic diversity in young growth on industrial dumps, since rare alleles from a theoretical point of view should be more often in a heterozygous state.

The selective advantage possibility of individuals of various isozyme loci which are heterozygous for the alleles is discussed in the literature (Chudzińska et al. 2014). On the other hand, the evaluation of the association of 6 quantitative characteristics with heterozygosis in 12 isozyme loci did not reveal their relationship (Savolainen and Hedrick 1995). This paper argues that a positive association can only be found with a very small population size, inbreeding, and high intrapopulation spatial structuring. In this case, the phenomenon of the 'apparent' advantage of heterozygotes, caused by other factors, and not the selectivity of alleles of isozyme loci in the heterozygous state, can manifest itself. At the same time, it is not excluded that under conditions of acute technogenic pollution of Scots pine stand with heavy metals, metabolically important enzymes can influence the formation of homo- and heterozygosity of populations (Chudzińska et al. 2014). But testing this possibility requires a separate study, involving genes that have a selective role. Our work, apparently, is the only research containing the evidence of increased intrapopulation differentiation and the formation of a relatively high genetic diversity of the Scots pine undergrowth in technogenic conditions on isozyme loci. Only in one paper (Prus-Głowacki and Nowak-Bzowy 1992) the polymorphism of ten isozyme loci of one sample of 10-15 year-old young growth growing under conditions of zinc contamination was studied. But the results obtained were not compared with similar data on the parent stand, but with the genetic diversity of 9 natural stands of Poland in areas outside the direct impact of industrial pollution.

Technogenic pollution of land is currently becoming a problem of the planetary level. In (Mahar et al. 2016) there is the information that there are more than 3.5 million polluted habitats in the European Union alone and about 600 thousand hectares are polluted with heavy metals in the USA is given The scale of the problem, the high cost of technical remediation methods stimulate the development of methods of phytoremediation for the extraction of heavy metals from the environment with plants and their accumulation in the roots and the aerial parts in metabolites in a less dangerous form. A recent review plants of 414 species - the hyperaccumulators of a heavy metal are listed (Midhat et al. 2019). Herbaceous plants dominate in this recommended list, although arboreal plants such as Scotch pine are well-known by the advantages for phytoremediation of polluted lands. Among them are resistance to heavy metals, the ability to grow in a wide range of environmental conditions, a developed root system and a large above-ground biomass, growth rate, etc. Particularly important are such bioecological properties as the abundance and long range of seed dispersal, their high germination capacity, which make it possible to effectively colonize new man-made habitats without human intervention. As a result of this study, it was shown that, in the technogenic zone of the mining enterprises, the undergrowth 
also forms a rich gene pool reproducing the gene resources of the local Scots pine population. It is spatially structured, which increases the resistance of the entire population to the effects of harsh industrial pollution. This is another argument for the point of view (Kulagin and Tagirova 2015) that leaving man-made lands for forest remediation — natural reforestation is promising, and this process should also be facilitated.

\section{CONCLUSIONS}

In extreme environment, the living organisms can form specific adaptation mechanisms not only to survive but also to multiply successfully. Thus, species with a broader range of ecological requirements are likely to reach domination.

This study is devoted to a phenomenon when the Scots pine not only survives under extreme conditions but also becomes genetically heterogeneous within one population and this heterogeneity is greater than it is usually observed in natural communities.

Such an adaptability enables the spread across territories that are extremely unfavorable for other plant species and exploited by humans. Findings may be used in large-scale cost-effective forest growing. Pine seedlings with a high adaptive potential and genetic heterogeneity are able to form stable communities in other technologically polluted areas. As a core of such pioneer communities, the emerging plant associations will be gradually enriched by other species of plants and animals that inhabit them. Thus, biodiversity in technologically polluted area will increase.

The continuation of this study seems necessary to answer such important questions: how widespread can be this scenario, how is it implemented on industrial lands with other availability of seeds? Moreover, the use of DNA markers that can detect the level of genetic population differentiation more informatively will be a promising solution.

\section{REFERENCES}

1. Belan, L., 2005: Ecological and geochemical state of the mining regions of the Bashkir Zauralye. Bulletin of the Orenburg state 6(44): 113-117.

2. Blanc-Jolivet, C., Yanbaev, Y., Kersten, B., Degen, B., 2018: A set of SNP markers for timber tracking of Larix spp. in Europe and Russia. Forestry 91(5): 614-628.

3. Chudzińska, E., Diatta, J., Wojnicka-Półtorak, A., 2014: Adaptation strategies and referencing trial of Scots and Black pine populations subjected to heavy metal pollution. Environmental Science and Pollution Research 21(3): 2165-2177.

4. Davis, B., 1964: Disc electrophoresis XI. Methods and application to human serum proteins. Annals of the New York Academy of Sciences 121: 404-427.

5. Forrest, I., Burg, K., Klumpp, R., 2000: Genetic markers: tools for identifying and characterizing Scotch pine populations. Forest Systems 9: 67-88.

6. Gabdrakhimov, K., Khayretdinov, A., Sultanova, R., Konashova, S., Konovalov, V., Sabirzyanov, I., Gabdelkhakov, A., Isyanyulova, R., Martynova, M., Blonskaya, L., 2018: Reproduction of stable pine forests in the Southern Urals. Journal of Engineering and Applied Sciences 13: 6494-6499.

7. Goncharenko, G., Silin, A., Padutov, V., 1993: Analysis of gene structure and differentiation in central and marginal Pinus sylvestris populations of Eastern Europe and Siberia. Silvae Genetica 29: 2019-2038. 
8. Kujala, S.T., Knürr, T., Kärkkäinen, K., Neale, D.B., Sillanpää, M.J., Savolainen, O., 2017: Genetic heterogeneity underlying variation in a locally adaptive clinal trait in Pinus sylvestris revealed by a Bayesian multipopulation analysis. Heredity (Edinb) 118(5): 413-423.

9. Kulagin, A., Tagirova, O., 2015: Forest plantations of the Ufa industrial center: current state in the conditions of anthropogenic impacts Ufa. Gilem, Pp 66-71.

10. Larionova, A., Ekart, A., 2011: Isoenzyme diversity and differentiation of marsh Scotch pine (Pinus sylvestris L.) populations in the Western Siberia. Eurasian Journal of Forest Research 14(1): 21-28.

11. Mahar, A., Wang, P., Ali, A., Awasthi, M.K., Lahori, A.H., Wang, Q., Li, R., Zhang, Z., 2016: Challenges and opportunities in the phytoremediation of heavy metals contaminated soils: a review. Ecotoxicology and Environmental Safety 126: 111-121.

12. Midhat, L., Quazzani, N., Hejjaj, A., Ouhammou, A., Mandi, L., 2019: Accumulation of heavy metals in metallophytes from three mining sites (Southern Centre Morocco) and evaluation of their phytoremediation potential. Ecotoxicology and Environmental Safety 160: 150-160.

13. Nei, M., 1972: Genetic distance between populations. American Naturalist 106: 283-291.

14. Ornstein, L., 1964: Disc-electrophoresis I. Background and theory. Annals of the New York Academy of Sciences 121: 321-349.

15. Prus-Głowacki, W., Nowak-Bzowy, R., 1992: Genetic structure of a naturally regenerating Scots pine population tolerant for high pollution near a zinc smelter. Water, Air \& Soil Pollution 62(3-4): 249-259.

16. Prus-Głowacki, W., Chudzińska, E., Wojnicka-Połtorak, A., Kozacki, L., Fagiewicz, K., 2006: Effects of heavy metal pollution on genetic variation and cytological disturbances in the Pinus sylvestris L. population. Journal of Applied Genetics 47(2): 99-108.

17. Savolainen, O., Hedrick, P., 1995: Heterozygosity and fitness: no association in Scots pine. Genetics 140: 755-766.

18. Jovanović V.S., Mitić V., Mandić S.N., Ilić M., Simonović S., 2015: Heavy metals in the post-catastrophic soils. In: Sherameti I., Varma A. (eds): Heavy metal contamination of soils. Soil Biology, Springer, Cham 44: 3-21.

19. Savolainen, O., Kujala, S.T., Sokol, C., Pyhäjärvi, T., 2011: Adaptive potential of northernmost tree populations to climate change, with emphasis on Scots pine (Pinus sylvestris L.). The Journal of Heredity 102(5): 526-536.

20. Sultanova, R., Gabdrahimov, K., Khayretdinov, A., Konashova, S., Konovalov, V., Blonskaya, L., Sabirzyanov, I., Martynova, M., Isyanyulova, R., Gabdelkhakov, A., 2018: Evaluation of ecological potential of forests. Journal of Engineering and Applied Sciences 13: 6590-6596.

21. Swofford, D., Selander, R., 1981: Biosys-1: a Fortran program for the comprehensive analysis of electrophoresis data in population genetics and systematic. Journal of Heredity 72: 281-283.

22. Tagirov, V., Yanbaev, Y., Tagirova, A., 2015: On environmental and genetic components of differences in growth in height of scotch pine on former farmlands. Bulletin of Bashkir University 20(3): 889-891.

23. Wachowiak, W., Salmela, M.J., Ennos, R.A., Iason, G., Cavers, S., 2011: High genetic diversity at the extreme range edge: nucleotide variation at nuclear loci in Scots pine (Pinus sylvestris L.) in Scotland. Heredity (Edinb) 106(5): 775-787.

24. Wójkiewicz, B., Cavers, S., Wachowiak, W., 2016: Current approaches and perspectives in population genetics of Scots Pine (Pinus sylvestris L.). Forest Science 62(3): 343-354. 
25. Yanbaev, Y.A., Bairamgulov, N.R., Redkina, N.N., Mullagulov, R.Y., 2007: Differentiation among populations of the Rhodiola iremelica Boriss. (Grassulaceae) in the Southern Urals. Russian Journal of Genetics 43(11): 1314-1318.

Yulai Yanbaev*, Rida Sultanova, Liubov Blonskaya Svetlana Bakhtina

Bashirir State Agrarian University

Federal State Budgetary Educational Institution of Higher Education 50-Letiya Octyabrya Street 34 45000 U UFA

Russia

*Corresponding author: Yanbaev_ua@mail.ru

Albina Tagirova, Vadim Tagirov

Bashikir State University

Federal State Budgetary Educational Institution of Higher Education

Zaki Validi Street 32 450076 UFA

Russia

Aleksey Kulagin

Ufa Institute of Biology of Ufa Research Center of Russian Academy of Sciences Prospect Octyabrya, 69 450054 UFA

Russia 
